\title{
Reproducible dispensing results
}

$A_{\text {presented its newly designed }}^{\text {t the Automatica trade fair, Scheugenflug AG }}$ Apresented its newly designed DesktopCNCell, a desktop dispensing cell that can dispense highly filled compounds accurately and with high levels of reproducibility. The piston metering unit is ideal for metering and dispensing abrasive and highly filled materials for small volume production runs and is mounted on an axis system which is of extremely high quality for this class of product. Other exhibits included a pre-production model of the process module 1.0. This modular metering and dispensing system can easily be integrated into production lines on the basis of the "plug \& play" principle.

For more information: Scheugenpflug AG,

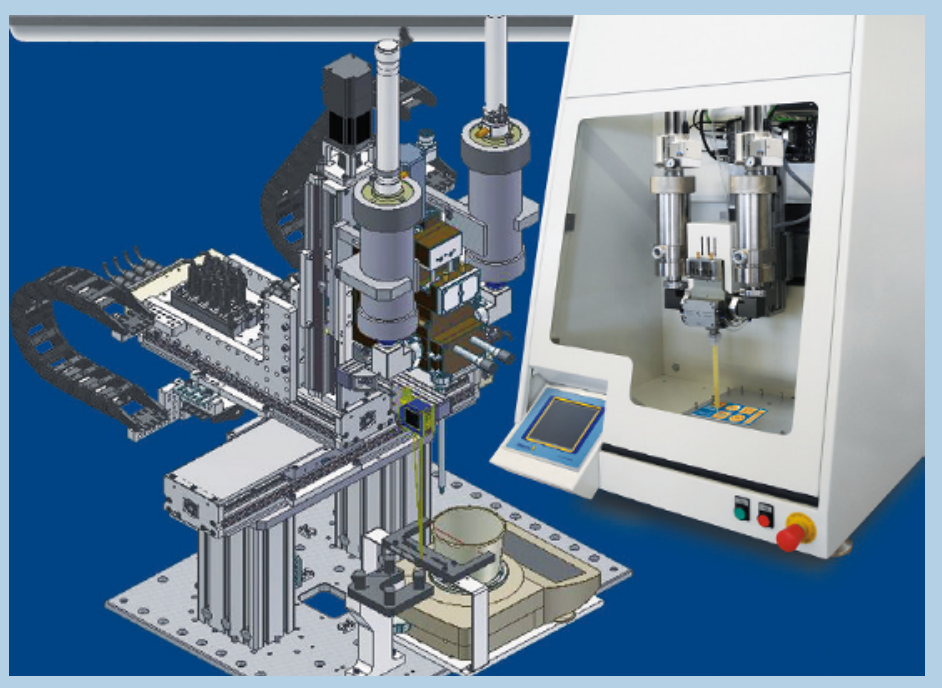
vertrieb.de@scheugenpflug.de

\section{Accurate dispensing}

$A_{\text {systems marketed under the Techcon Systems brand } \text { these }}^{\text {t }}$ high-precision systems are designed to dispense fluids accurately and reproducibly for use in the aerospace industry, industrial assembly processes, medical technology, military applications and the electronics industry. They can be used to process adhesives, soldering pastes, fluxing agents, sealing compounds, oils, dyes and solvents. A variety of different analogue and digital control units

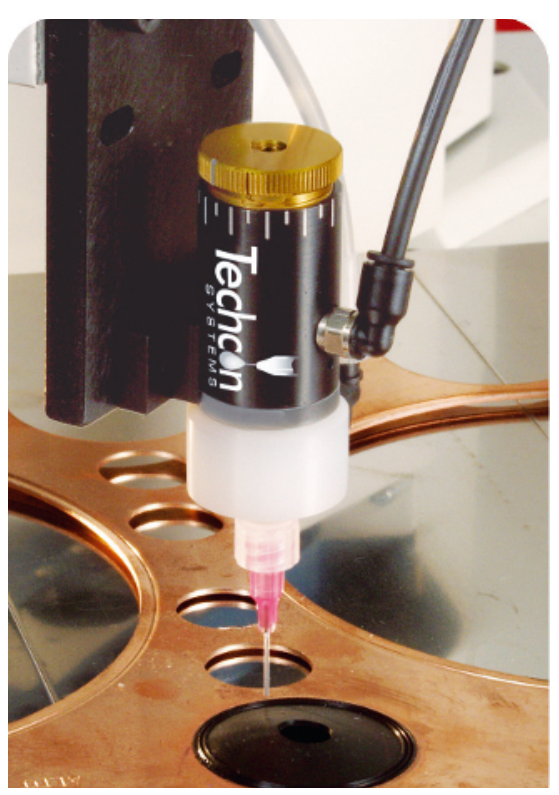

is available for different applications. There is also a comprehensive series of dispensing valves, ranging from simple diaphragm valves through to splash valves. In addition to the dispensing systems, a new vacuum mixer, UV curing systems and single-component deep-freeze adhesives were also exhibited at the trade fair.

For more information: APM Technica AG, CH-9435 Heerbrugg, www.apm-technica.com, info@apm-technica.com

\section{Improved epoxy, PU and MMA adhesives}

n order to open up an even larger market for its products in the field of vehicle bodies and modular structures, Dow Automotive Systems plans to expand its range of adhesives by 2013 to include products with new properties. These will be aimed at manufacturers, sys-

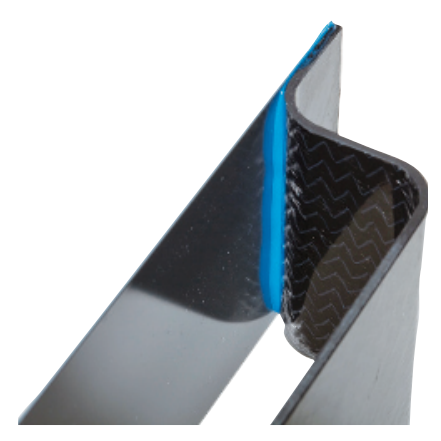
tem suppliers and the spare parts and repair market.

For example, four new formulations with improved stability and corrosion protection properties and increased cost-effectiveness have been added to the epoxy-based Betamate range. The polyurethane adhesives marketed under the name Betaforce are characterised by long working times and rapid adhesion. They need little surface preparation and are therefore ideal for less complex, high-quality sandwich solutions and for bonding composites.

A new Betafuse methyl methacrylate (MMA) adhesive is now available for bonding composites and metals. It has low VOC emission levels, a good ratio between the working time and the curing time and also requires very little surface preparation.

Other products for sealing vehicle bodies have also been added to the portfolio.

For more information: www.dowautomotive.com 